\title{
Compliance with Brain Trauma Foundation Guidelines in TBI Patients
}

\author{
Shahla Siddiqui*, Mariam Quindipan and Wang Jiexun \\ Department of Anaesthesia, Khoo Teck Puat Hospital, Singapore
}

"Corresponding author: Shahla Siddiqui, Department of Anaesthesia, Khoo Teck Puat Hospital, Singapore, Tel: 0065-6602 2317; 0065-97966257; E-mail: siddiqui.shahla@ktph.com.sg

\begin{abstract}
Aims: The aim of this audit done prior to the release of the $4^{\text {th }}$ guidelines was to audit the compliance with the brain trauma foundation guidelines in our Surgical Intensive Care Unit from Dec 2013 to Mar 2014.

Methods: All adult traumatic brain injury patients admitted to the SICU between December 2013 and March 2014 were included. The third edition of the BTF guidelines was taken as a standard to assess compliance. A computerized ICU database established in 2011 allowed access to the patient records and all data was cross checked with the hospital patient record system.

Results: A total of 28 patients were admitted to the SICU during the audit period. 15 variables were checked from the database and corroborated from the hospital records. The variables were collected at 24 hours after admission. All patients were with low Glasgow coma scale (GCS) and admitted to the ICU for neuro monitoring. Of the 15 variables recommended the compliance rate was $60.7 \%$. The ICU mortality for this group of TBI patients during this period was $25 \%$.

Conclusions: Our audit shows a higher compliance rate and an acceptable mortality rate. Further studies will be required to see the mortality benefit between groups as well as development of local protocols to improve adherence to the guidelines suggested.
\end{abstract}

Keywords: Brain trauma; TBI patient; Mortality rate; Glasgow coma scale

Received Date: April 23, 2018; Accepted Date: May 17, 2018; Published Date: May 24, 2018

\section{Audit Report}

\section{Introduction}

Traumatic brain injury remains the most complex form of trauma and despite decades of progress mortality remains high. Traumatic brain injury requires close monitoring, early therapy and thresholds for treatments in a coordinated manner. Neuro -surgeons and neuro-intensivists have been leading the research and guideline development and the new guidelines add new evidence. The Brain Trauma Foundation guidelines serve as a standard. The new 14 recommendations have been modified and added since the last edition in 2007 of the BTF guidelines whilst 14 have remained the same.

Citation: Shahla Siddiqui, Compliance with Brain Trauma Foundation Guidelines in TBI Patients. J Clin Cases Rep 2018: 1(2): 63-66. DOI: https://doi.org/10.46619/joccr.2018.1-1014 
www.tridhascholars.org | July-2018

Most of the proactive recommendations are Level II and above whilst the avoidance of steroids is a Level I recommendation. Other therapeutic recommendations include a large unilateral craniectomy to relieve pressure on the brain, avoidance of early prophylactic hypothermia, hyperosmolar therapy with mannitol, use of an EVD drain to lower Intracranial pressures (ICP), avoidance of hyperventilation, use of sedation and barbiturates for intractable intracranial hypertension, transjejunal feeding for basic caloric requirements, infection prophylaxis, DVT prophylaxis, use of blood pressure, ICP and CPP thresholds as well as advance cerebral oxygen monitoring. The difference between the 3rd and the 4th guidelines include the addition of drainage of CSF to reduce ICP.

Previous literature shows a low rate of compliance but recently the CDC (center for disease control) has estimated a $50 \%$ reduction of complications and mortality in TBI patients if the guidelines were maximally adhered to with potential savings of up to 3 billion dollars per annum. Several audits done in the early 2000s have shown a reduction in mortality and improvement in outcomes of TBI patients [1]. The adherence to individual recommendations varied between 40-50\% in these studies. There were no studies done where an overall compliance was studied [2]. The BTF states that the guidelines serve as a guide to develop best clinical practice protocols in individual settings and admit to there being some gaps in evidence. Most of the recommendations come from weak evidence and should be adapted to specific situations [3].

\section{Aim}

The aim of this audit done prior to the release of the 4th guidelines was to audit the compliance with the brain trauma foundation guidelines in our Surgical Intensive Care Unit from December 2013 to March 2014.

\section{Audit Standards}

The Brain Trauma Foundation (BTF) guidelines serve as basic evidence based recommendations with general best practices for brain trauma patients. The brain trauma foundation is a non- profit organization established in the 1980s to improve outcomes for traumatic brain injury (TBI) patients worldwide through evidence based guideline development. The current guidelines are the fourth iteration based on 189 publications that address treatment interventions, monitoring, and thresholds that are specific to TBI. The current guidelines address 28 recommendations covering 18 topics.

\section{Methods}

Our 14 bedded surgical ICU (SICU) serves a population of 0.74 million in the North of Singapore. All traumatic brain injury patients are admitted under the Neurosurgery department at our hospital with those requiring close neurological monitoring admitted to the Surgical Intensive care unit. Of the 14 beds 8 are intensive care whilst six are high dependency. Our surgical ICU is a closed intensivist run unit with close co-management by the neurosurgical team.

For the purposes of this retrospective audit all adult traumatic brain injury patients admitted to the SICU between December 2013 and March 2014 were included. The third edition of the BTF guidelines was taken as a standard to assess compliance. A computerized ICU database established in 2011 allowed access to the patient records and all data was cross checked with the hospital patient record system. The variables included treatment, monitoring and threshold recommendations by the BTF. A total of 15 recommendations were evaluated for compliance. ICU Mortality was also recorded as a secondary outcome measure. 


\section{Results}

A total of 28 patients were admitted to the SICU during the audit period. 15 variables were checked from the database and corroborated from the hospital records. The variables were collected at 24 hours after admission. All patients were with low Glasgow coma scale (GCS) and admitted to the ICU for neuro monitoring. Of the 15 variables recommended the compliance rate was $60.7 \%$. The ICU mortality for this group of TBI patients during this period was $25 \%$. The variables and their compliance are given in the table below.

\begin{tabular}{|c|c|c|c|c|c|}
\hline S.No. & Variable & Recommendation & Compliance & Percentage & Remarks \\
\hline 1 & $\begin{array}{l}\text { Blood pressure } \\
\text { thresholds used }\end{array}$ & Recommended IIA & $26 / 28$ & 92.9 & $\begin{array}{c}\text { Maintaining SBP at } \geq 100 \mathrm{~mm} \mathrm{Hg} \\
\text { for patients } 50 \text { to } 69 \text { years old or } \\
\text { at } \geq 110 \mathrm{~mm} \mathrm{Hg} \text { or above for } \\
\text { patients } 15 \text { to } 49 \text { or over } 70 \text { years } \\
\text { old }\end{array}$ \\
\hline 2 & $\begin{array}{c}\text { No hyperosmolar } \\
\text { therapy used in first } 24 \\
\text { hours }\end{array}$ & $\begin{array}{c}\text { Restricted to } \\
\text { herniation Level III } \\
\text { C }\end{array}$ & $19 / 28$ & 67.9 & $\begin{array}{l}\text { Occasionally mannitol or HS } \\
\text { saline used in severe cases. }\end{array}$ \\
\hline 3 & $\begin{array}{l}\text { No prophylactic } \\
\text { hypothermia used }\end{array}$ & $\begin{array}{l}\text { Not recommended } \\
\text { IIB }\end{array}$ & $23 / 28$ & 82.1 & $\begin{array}{c}\text { Temperature above } 36 \text { degrees C } \\
\text { maintained (fever avoided by } \\
\text { cooling measures) }\end{array}$ \\
\hline 4 & $\begin{array}{l}\text { Decompressive } \\
\text { craniectomy done }\end{array}$ & Recommended IIA & $13 / 28$ & 50 & $\begin{array}{c}\text { Done when ICP is intractably } \\
\text { high }\end{array}$ \\
\hline 5 & $\begin{array}{l}\text { Infection prophylaxis in } \\
\text { first } 24 \text { hrs. used }\end{array}$ & $\begin{array}{l}\text { Recommended Level } \\
\text { IIA }\end{array}$ & $18 / 28$ & 64.3 & \\
\hline 6 & $\begin{array}{l}\text { Non pharmacological } \\
\text { DVT prophylaxis used }\end{array}$ & $\begin{array}{l}\text { Recommended Level } \\
\text { III }\end{array}$ & $26 / 28$ & 92.9 & Stockings used \\
\hline 7 & ICP monitoring done & $\begin{array}{l}\text { Recommended Level } \\
\text { IIB }\end{array}$ & $15 / 28$ & 53.6 & $\begin{array}{l}\text { With ICP monitor placed within } \\
24 \text { hours }\end{array}$ \\
\hline 8 & ICP thresholds used & $\begin{array}{l}\text { Recommended Level } \\
\text { IIB }\end{array}$ & $15 / 28$ & 53.6 & $\begin{array}{c}\text { ICP maintained less than } 25 \mathrm{~cm} \\
\mathrm{H} 20 \text { with sedation or } \\
\text { hyperosmolar therapy }\end{array}$ \\
\hline 9 & CPP thresholds used & $\begin{array}{l}\text { Recommended Level } \\
\text { IIB }\end{array}$ & $15 / 28$ & 53.6 & $\begin{array}{l}\text { MAP maintained high with } \\
\text { vasopressors in order to achieve } \\
\text { CPP of } 60 \text { and above }\end{array}$ \\
\hline 10 & $\begin{array}{c}\text { Advanced cerebral } \\
\text { oxygen monitoring and } \\
\text { thresholds used }\end{array}$ & $\begin{array}{l}\text { May be used Level } \\
\text { III }\end{array}$ & $0 / 28$ & 0 & JV O2 sat $<50 \%$, not done \\
\hline 11 & $\begin{array}{c}\text { Prophylactic } \\
\text { barbiturate and } \\
\text { Propofol sedation done }\end{array}$ & $\begin{array}{l}\text { Recommended Level } \\
\text { IIB }\end{array}$ & $15 / 28$ & 53.6 & 2 patients also received Precedex \\
\hline 12 & Nutrition in first $24 \mathrm{hrs}$. & $\begin{array}{l}\text { Recommended Level } \\
\text { IIA }\end{array}$ & $14 / 28$ & 50 & \\
\hline 13 & $\begin{array}{c}\text { Anti-seizure } \\
\text { prophylaxis given }\end{array}$ & $\begin{array}{l}\text { Recommended Level } \\
\text { IIA }\end{array}$ & $16 / 28$ & 57.1 & \\
\hline 14 & $\begin{array}{c}\text { Hyperventilation not } \\
\text { done }\end{array}$ & $\begin{array}{c}\text { Not recommended } \\
\text { Level IIB } \\
\end{array}$ & $18 / 28$ & 64.3 & \\
\hline 15 & Steroids not given & $\begin{array}{c}\text { Contraindicated } \\
\text { Level I }\end{array}$ & $21 / 28$ & 75 & \\
\hline
\end{tabular}

Table 1: Compliance with BTF guidelines

Note: ICP: Intracranial Pressure, CPP: Cerebral Perfusion Pressure, JV: Jugular Venous

\section{Discussion}

TBI is common and a major public health problem contributing to one of the major causes of mortality and disability [4]. Despite a progressive and significant reduction in mortality no single treatment has been shown to improve outcome. 
www.tridhascholars.org | July-2018

Management continues to be focused on prevention of secondary injuries and maintenance of CPP [4]. Since the advent of BTF guidelines mortality has reduced however compliance remains poor. Our audit shows a higher compliance rate and an acceptable mortality rate. Further studies will be required to see the mortality benefit between groups as well as development of local protocols to improve adherence to the guidelines suggested.

Our audit had a few limitations. We had a small number of patients who could be included as our SICU is a mixed surgical ICU and our ICU beds are also limited. Further extending the audit and repeating the cycle may provide more holistic information.

\section{Conclusion}

This audit is one of few done in the field of TBI following the new BTF guidelines and shows a promising rate of compliance. Further study is needed to validate these guidelines in clinical practice and study the outcomes of following such guidelines in neurocritical care.

\section{Recommendation}

We recommend closing the loop by improving compliance with re audit at intervals as well as research into mortality benefits as well as spreading the audit across other centers.

\section{References}

1. Hemphill JC (2007) Management and prognosis of severe traumatic brain injury, Journal of Neurotrauma 200724 : S1-S106.

2. Talving P, Karamanos E, Teixeira PG, et al. (2013) Intracranial pressure monitoring in severe head injury: compliance with Brain Trauma Foundation guidelines and effect on outcomes: a prospective study. Journal of Neurosurgery 119(5): 1248-1254.

3. The Association of Anaesthetists of Great Britain and Ireland (2006) Recommendations for the Safe Transfer of Patients with Brain Injury. Portland, London.

4. National Collaborating Centre for Acute Care (2007) Head Injury: Triage, Assessment, Investigation and Early Management of Head Injury in Infants, Children and Adults. London: National Collaborating Centre for Acute Care (UK). 